\title{
Isolating a functionally relevant guild of fungi from the root microbiome of Populus
}

\author{
Gregory Bonito ${ }^{1}$, Khalid Hameed ${ }^{2}$, Rafael Ventura ${ }^{2}$, Jay Krishnan ${ }^{2}$, Christopher Schadt ${ }^{3}$, \\ and Rytas Vilgalys ${ }^{2}$ \\ ${ }^{1}$ Department of Plant Soil and Microbial Sciences, Michigan State University, East \\ Lansing MI 48824, USA \\ ${ }^{2}$ Biology Department, Duke University, Durham NC 27708, USA \\ ${ }^{3}$ Biosciences Division, Oak Ridge National Laboratory, Oak Ridge TN 37831, USA
}

Corresponding author: Gregory Bonito

Email: bonito@msu.edu

Phone: (517) 884-6958

Fax: (517) 353-5174 
Plant roots interact with a bewilderingly complex community of microbes, including rootassociated fungi that are essential for maintaining plant health. To improve understanding of the diversity of fungi in the rhizobiome of Populus deltoides, $P$. trichocarpa and co-occuring plant hosts Quercus alba and Pinus taeda, we conducted field and greenhouse studies and sampled, isolated, and characterized the diversity of culturable root-associated fungi on these hosts. Using both general and selective isolation media we obtained more than 1800 fungal isolates from individual surface sterilized root tips. Sequences from the ITS and/or D1 - D2 regions of the LSU rDNA were obtained from 1042 of the $>1800$ pure culture isolates and were compared to accessions in the NCBI nucleotide database and analyzed through phylogenetics for preliminary taxonomic identification. Sequences from these isolates were also compared to 454 sequence datasets obtained directly from the Populus rhizosphere. Although most of the ectomycorrhizal taxa known to associate with Populus evaded isolation, many of the abundant sequence types from rhizosphere and endosphere 454 datasets were isolated, including novel species belonging to the Atractiellales. Isolation and identification of key endorrhizal fungi will enable more targeted study of plant-fungal interactions. Genome sequencing is currently underway for a subset of our culture library with the aim of understanding the mechanisms involved in host-endophyte establishment and function. This diverse culture library of fungal root associates is a valuable resource for metagenomic research, experimentation and further studies on plant-fungal interactions.

Keywords; Populus deltoides, Populus trichocarpa, endophytes, ectomycorrhizal fungi, ecological interactions, rhizobiome.

\section{Introduction}

Plant roots are known to harbor a diverse community of fungi that perform a variety of roles in the rhizosphere as saprotrophs, symbiotic mutualists - including arbuscular mycorrhizal fungi (AMF) and ectomycorrhizal fungi (EMF), and pathogens (Smith and 
Read 2008). Through environmental sequencing and metagenomic approaches we have been able to detect and classify much of the fungal diversity in plant roots, however the impact of these living fungi on plant health or ecosystem functions remains obscure because these fungi are only known from DNA sequences (Gottel et al. 2011). To address this limitation of metagenomic approaches we aimed to isolate a functionally relevant guild of fungi from the Populus rhizobiome.

Populus is an economically important genus of woodland and riparian trees and is distinctive in its rapid growth and ability to form both arbuscular and ectomycorrhizas (Lodge 1989). Populus also associates with a high diversity of root endophytic fungi and bacteria, many of which are likely to play important roles in the rhizosphere and in soils (Shakya et al. 2013). While there is growing interest in the use of Populus feedstock for energy production, its associated belowground fungal diversity remains largely uncharacterized and poorly understood. A better understanding of these fungi and their biology is relevant to plant growth and health.

Belowground ectomycorrhizal interactions in Populus were recently reviewed (Podila et. al 2009). These authors reiterated the need for further functional genomics and ecological metabolomic studies to address the biology and ecology of the plant-fungalsoil interface. Soil water tension has been reported as one factor that affects mycorrhizal colonization levels in Populus deltoides (Lodge 1989), with greater ectomycorrhizal colonization in soils with median levels of moisture. Ectomycorrhizal associates of Populus include species of Laccaria, Inocybe, Hebeloma, Cortinarius and Tuber (Baum and Makeschin 2000; Bois et al. 2005; Podila et al. 2009; Gottel et al. 2011; Guevara et al. 2013). Soil nutrient levels and plant genotype have also been reported to influence rhizosphere community structure and function (Baum and Makschin 2000; Beauchamp et al. 2005; Karlinski et al. 2010; Courty et al. 2011). A better knowledge of the structure, development and regulation of the fungal associates of Populus has broad relevance to plant productivity (Baum et al. 2002; Judith 2009; Liang 2010), plant tolerance to toxic levels of chemicals in soils (Krpata 2008; Khosla et 

microorganisms (Shaul et al. 1999).

Many of the pre-molecular studies on belowground fungal associates of Populus are descriptive in nature (Kaldorf et al. 2005; Zhang et al. 2010; Mueller et al. 2012) and ecological in scope (Helm et al. 1996; Klironomos et al. 1997). These studies indicate that diversity of both EMF and AMF varies across Populus species, genotypes, and environments (Lodge 1989; Zhong 1995). However, our recent studies of root associated microbial communities using directed ITS, 28S and 16S rDNA high throughput sequencing approaches have shown that traditional AMF and EMF taxa are present but not dominant in natural Populus deltoides ecosystems (Gottel et al. 2011; Shakya et al. 2013), or in P. trichocarpa in plantation systems (Schadt et al. unpublished). Rather, Populus appears to associate with a high diversity of root endophytic fungi and bacteria, which currently have unknown or poorly understood roles in rhizosphere and root function. Using direct rRNA and more traditional microscopic and isolation approaches other researchers have also confirmed Populus spp. harbor a high diversity of fungi in their roots, including both traditional mycorrhizal and non-mycorrhizal taxa (Cripps and Miller 1995; Visser et al. 1998; Khasa et al. 2002; Jabeen et al. 2012; Gottel et al. 2011; Karlinski et al. 2013; Shakya et al. 2013; Bonito et al. 2014). Much of this belowground fungal diversity is uncharacterized, phylogenetically and functionally, and remains underexploited.

To begin to disentangle the complexity in structure and function of fungi associated with the Populus rhizobiome we carried out intense efforts to isolate endophytic and mycorrhizal fungi from healthy Populus roots. To accomplish this goal, fungi were isolated from fresh surface sterilized Populus roots collected from three sources: (1) natural stands of $P$. deltoides in eastern North America; (2) a common garden experiment established with genotypes of $P$. trichocarpa from across its geographic range in western North America (below); (3) Populus cuttings planted in field soil and reared under controlled greenhouse conditions (i.e. trap-plants). This sampling included 
multiple Populus species and genotypes and roots from co-occuring Quercus alba (white oak) and Pinus taeda (loblolly pine) species.

\section{Materials and Methods}

\section{Sampling roots of Populus}

Root samples of $P$. deltoides were collected from both natural populations of mature $P$. deltoides along the Yadkin river in NC (see Shakya et al. 2013) and diverse $P$. trichocarpa genotypes planted in common garden plots in $\mathrm{CA}, \mathrm{OR}$ and British Columbia (see Slavov et al. 2012). To obtain field samples from $P$. deltoides and $P$. trichocarpa, roots from adult trees were traced out from the trunk with hand tools until clusters of fine roots could be sampled, as previously described (Shakya et al. 2013). Encountered fine roots $(20-50 \mathrm{~g})$ were harvested and then immediately placed in zip-lock bags and under ice. These samples were stored at $4^{\circ} \mathrm{C}$ until isolations were made (within $3 \mathrm{~d}$ ). Roots of $P$. trichocarpa were collected in a similar manner from common garden field sites in Placerville CA, Corvallis OR and Clatskanie WA that had been established with natural genotypes of $P$. trichocarpa (Slavov et al. 2012). At least five individual genotypes were sampled from each common garden site. Additionally we obtained isolates from Populus cuttings rooted in soil from several of these sites (see Bonito et al. 2014). Soil and Populus cuttings were stored at $4^{\circ} \mathrm{C}$. Prior to use these $30 \mathrm{~cm}$ long cuttings were soaked overnight in tap water and then surface sterilized in a 10 min bath of $3 \% \mathrm{H}_{2} \mathrm{O}_{2}$. Cuttings were triple-rinsed with tap water and potted in a mixture containing 30-50\% freshly collected field soil mixed into sterilized sand. Soils for trap-plant experiments were collected from $P$. trichocarpa common garden experiment sites established with natural genotypes of (Slavov et al. 2012), and from natural Populus stands along the Yadkin river (Shakya et al. 2013; Bonito et al. 2014). Trap-plants were grown for 5 months in the Duke Phytotron under controlled environmental conditions of $18 \mathrm{~h}$ days, 6 $\mathrm{h}$ nights, with $400 \mu \mathrm{mol}$ photons $\mathrm{m}^{-2} \mathrm{~s}^{-1}$ and a day temp of $21.1^{\circ} \mathrm{C}$, night temp of $15.6^{\circ} \mathrm{C}$, and relative humidity of $60 \%$ during the day and $85 \%$ at night as described in Bonito et al. (2014). In addition to sampling $P$. deltoides $(n=34)$ and $P$. trichocarpa $(n=152)$, isolations were made from a smaller number of root samples from Pinus taeda $(n=8)$ and Quercus alba $(n=8)$ trap-plants rooted in the soils above. We include these as 
outgroup taxa that could be contrasted with Populus. In total we sampled roots from 202 individual plants.

\section{Isolating fungi from plant roots}

Both native and trap-plant root samples were harvested and thoroughly washed with tap water and a solution of $0.1 \%$ Tween20 to remove soil debris and adhering soil particles. Sections of healthy looking roots (2-3 cm from root-tip and beyond) were selected under a dissecting microscope. We included roots that both appeared to be colonized by ectomycorrhizal fungi or uncolonized. Root sections were wrapped in pre-sterilized squares of synthetic fiber cloth $\left(6-8 \mathrm{~cm}^{2}\right)$ and surface sterilized by submerging in $3 \%$ $\mathrm{H}_{2} \mathrm{O}_{2}$ for $1 \mathrm{~min}$, followed by two washings with sterilized distilled water. Sterility of the surface the roots was verified by streaking root segments across non-antibiotic media. 1-3 mm pieces of surface sterilized roots were plated onto modified Melin Norkrans medium (MMN) supplemented with $100 \mathrm{mg} \mathrm{L}^{-1}$ chloramphenicol and streptomycin. To target basidiomycetes, we also employed MMN or $1.5 \%$ malt extract agar (MEA) plates supplemented with Benomyl (4mg L ${ }^{-1}$ ) (Thorn et al. 1996).

Cultured material was observed daily. Fast growing fungi were aseptically removed to facilitate growth of slower growing fungi and increase the diversity of isolates obtained. Fungal growth from the root tips was examined under magnification and leading edges of the hyphae were sub-cultured onto the same media until a pure culture was obtained. Pure culture isolates were stored on agar slants and small discs cut from actively growing cultures and submerged in sterile distilled water for future use. A subset of representative strains have been deposited at the CBS culture collection (Utrecht, Netherlands).

\section{Molecular diagnosis}

To identify fungal isolates, DNA was extracted from mycelium by placing a small amount of tissue in $20 \mu \mathrm{l}$ of extraction solution (Sigma) and heating at $95^{\circ} \mathrm{C}$ for $10 \mathrm{~min}$. We added $60 \mu \mathrm{l}$ of bovine serum albumin (BSA 3\%) to the lystate and directly amplified the ITS and LSU rDNA with the primers ITS1f/ITS4 andLROR/LR3 (Vilgalys and Hester 1990; Gardes et al. 1991) to obtain DNA barcodes for these isolates (Schoch et al. 
2012). The PCR protocol was as follows: reaction mixtures contained $25 \mathrm{ng}$ of DNA, 50 ng of each primer, $0.2 \mathrm{mM}$ dNTPs, $0.5 \mathrm{U}$ Taq DNA polymerase, $10 \mathrm{mM}$ Tris $-\mathrm{HCl}(\mathrm{pH}$ 8.3), $2.0 \mathrm{mM} \mathrm{MgCl}_{2}$, and $0.1 \mathrm{mg} \mathrm{ml}^{-1}$ bovine serum albumin. Amplification conditions on a 2720 thermocycler (Applied Biosystems, Foster City, CA) included an initial denaturation step at $95^{\circ} \mathrm{C}$ for $5 \mathrm{~min}$ followed by 30 cycles of $95^{\circ} \mathrm{C}$ for $30 \mathrm{~s}, 50^{\circ} \mathrm{C}$ for $15 \mathrm{~s}$ and $72^{\circ} \mathrm{C}$ for $1.25 \mathrm{~min}$ and concluded with a $7 \mathrm{~min}$ extension at $72^{\circ} \mathrm{C}$. Amplicons were Sanger sequenced bidirectionally on an ABI3730XL automated sequencer (Applied Biosystems, Carlsbad, CA). Sequences were identified by comparing them to accessions in the NCBI nucleotide database with BLAST (Altschul et al. 1990) (http://www.ncbi.nlm.nih.gov/genbank/) and were aligned to closely related taxa and analyzed using phylogenetic methods. Sequenced isolates were clustered into OTUs (operational taxonomic units) using $97 \%$ sequence similarity (for ITS) or $99 \%$ (for LSU). ITS extractor was used to selectively extract the ITS1 and ITS2 regions from each of the sequences (Nilsson et al. 2010). By removing the conserved 5.8S domain and LSU and SSU sequence at the ends of the read, more reliable clustering of OTUs can be obtained because clusters are based solely upon the variable regions, rather than regions that are conserved across a high diversity of fungi and therefore taxonomically uniformative. The USEARCH algorithm (Edgar 2010) was used to cluster ITS1 \& ITS2 sequences into OTUs. LSU sequences were aligned in MUSCLE (Edgar 2004) and unalignable characters were excluded in Mesquite (Maddison and Maddison 2009). Most parsimonious trees were inferred in PAUP* (Swofford 2002). The interactive tree of life software (ITOL - http://itol.embl.de) was used to visualize relationships amongst isolates, geographic and host origins. Sequences obtained in this study have been submitted to GenBank (JX243744-JX244069; KC007130-KC007340; KF428214KF428718) - see Supplemental table 2.

Comparison of fungal diversity in Populus roots obtained through culture and high throughput culture-independent techniques

To determine the correspondence between molecular and culture-based assessments of fungal diversity, we used sequences of ITS and LSU rDNA obtained from fungal isolates through Sanger sequencing (above) and compared these to complementary 
sequence datasets obtained through 454 pyrosequencing of Populus endosphere and rhizosphere samples, available in the NCBI Sequence Read Archive (SRA) under the accession number SRP034435 and BioProject accession PRJNA209455 (Shakya et al. 2013; Bonito et al. 2014). Specifically, sequence datasets were merged and then OTUs were picked from this merged dataset and classified taxonomically following the UPARSE pipeline as published in Bonito et al. (2014), clustering OTUs at 97\% sequence similarity and grouping them by whether they were detected by cultureindependent metagenomic techniques, by culturing, or both, and were sorted by rank abundance. Fungal taxonomy was assigned to fungal isolates at the lowest taxonomic level that we could be confident in. This was done using multiple approaches that included BLAST searches against the UNITE 7.0 ITS reference database, queries with the RDP Bayesian Classifier, and manual BLAST searches to NCBI combined with phylogenetic analyses.

\section{Statistical analyses}

To determine if the diversity of fungal isolates differed across soil types and host genera, two-sided tests of proportions were performed using R 3.0.1 to test whether well sampled isolates were over or under-represented in particular soils or hosts. To mark the presence of statistical evidence, a $5 \%$ significance level was chosen; to mark the presence of strong statistical evidence, a $1 \%$ significance level was chosen. Chisquared tests were carried out to determine whether differences in the isolation of specific taxa between soils and hosts were significant.

\section{Results}

Diversity, identity and distribution of fungal isolates

Over 1800 fungal isolates were obtained from surface sterilized roots of Populus, Quercus, and Pinus. These isolates were grouped by morphotype resulting in over 120 distinguishable colony types (Fig 1). While an abundance of Ilyonectria, Fusarium, Mortierella, Trichoderma and other taxa were distinguishable based on colony growth, color and sporulation, many isolates were of sterile mycelium or asexual ascomycetes 
and species delimitations within these genera are nearly impossible to make based on morphology alone. Thus, DNA barcode sequences were determined for a subset of 1042 of these isolates including multiple replicates from each morphotype when available. Stringent OTU picking with the USEARCH algorithm resulted in 97 OTUs based on the ITS1 and 98 OTUs based on the ITS2 region (excluding singletons; including singletons OTU counts were 220 and 200, respectively). Although many of the OTUs had high identity blast hits, in some cases the taxonomic identity of the isolates could not be confirmed because top hits were from environmental sequences. Using both ITS and LSU, the most abundantly isolated fungal OTUs from Populus could be identified as Leptodontidium (83 isolates), Cylindrocarpon pauciseptatum (69 isolates), Atractiella sp. (51 isolates), Fusarium oxysporum (46 isolates), and three OTUs of Ilyonectria (45, 44, 40 isolates each) (Fig 2). Other fungi isolated from Populus roots (at lower abundance) included species of Sordariomycetes, Melinomyces, Paraphoma, Phomopsis, Exophiala, Rhizoctonia, Heliotiales, Cadophora, Corticiaceae, Lachnum, Mortierella, and Flagelloscypha (Fig 3; Table S2).

Of the sequenced isolates 710 were from $P$. trichocarpa, 206 from $P$. deltoides, 71 from Pinus taeda and 55 from Quercus alba. These accounted for 55, 26, 12 and 7 OTUs, respectively (excluding singletons), for each of these host species. Most of the dominant taxa could be isolated from both eastern US and western US soils, with no clear pattern of biogeographical provenance. Many of the dominant taxa could be isolated from both P. deltoides and P. trichocarpa, and in some cases Quercus and Pinus too, suggesting broad host range. Clear exceptions to this included Phialocephala and Oidiodendron spp., which were commonly isolated from Pinus (Figs $2 \& 3$ ) but not other plant hosts. Similarly, Melinomyces were primarily isolated from $P$. trichocarpa grown in soils from the west coast (WA \& OR) (Fig 3). We observed differences in the isolation frequency of some of the more abundant taxa with different soils and hosts. For instance, Atractiella sp. was isolated from both $\mathrm{NC}$ and CA soils, but was statistically more commonly isolated from $C A(P<0.001)$. Chi square tests indicate that the isolation frequency of Ilyonectria from Populus was significantly greater than expected compared to their isolation from Pinus ( $P=0.011$ ) (Fig S1). Similarly, an unidentified Sordariomycete OTU 
was isolated from Quercus at a significantly greater frequency $(P=0.001)$ than from Populus. Finally, several frequently isolated fungi including Leptodontidium, Phomopsis and Exophiala were only isolated from Populus roots, and thus appear to be limited to that host. While we were able to isolate many (but not all) fungi detected through metagenomic studies using next generation sequencing, a lot of fungi including mycorrhizal species evaded isolation (Supplementary table 3). Overall, a higher diversity of fungi was detected from high-throughput (454) sequencing than from culturing, with 99 OTUs overlapping between the two methods. These included five of the top ten most abundant fungi detected through culture-independent approaches (Fig $4)$.

\section{Discussion}

Cultivating the core Populus mycobiome

With over 1800 isolates and 1042 DNA barcoded isolates generated, this research makes a significant contribution to establishing baseline resources for understanding the core members of the endorrhizal guild of fungi able to live inside of Populus roots. A large number of our $>200$ isolates represent previously uncultured fungi, based upon BLAST results, half of which were singletons. The majority of our sequenced (88\%) isolates originated from Populus trichocarpa and P. deltoides. Few differences in the community of isolated endorrhizal fungi were evident between these hosts. Exceptions to this were the greater than expected isolation frequency of Atractiella, Phomopsis and Melinomyces isolates from $P$. trichocarpa, and the greater than expected frequency in the isolation of fungi belonging to the Chaetosphaeriaceae and Ophiostomaceae on $P$. deltoides. However, it is difficult to determine whether these results are due to host biases, methodological biases, or other factors that are soil, environmental or sample dependent. For both Populus hosts a single OTU Leptodontidium species was the most common fungal taxon isolated from roots. Fusarium, llyonectria, and other fungal species belonging to the Heliotiales were also commonly isolated. The incidence of fungi belonging to groups of fungi traditionally thought of more as plant pathogens (such as those in the Nectriaceae and Pleosporaceae) is interesting, particularly since isolates were made from fresh healthy root tissue. Future studies with representative isolates 
are planned to better characterize the ecological roles of these isolates and their interactions with plants.

While Quercus alba and Pinus taeda were sampled less intensively, even with limited sampling a greater than expected incidence of a particular sordariomyete OTU from Quercus was evident, as was the isolation of Phialocephala and Oidiodendron OTUs only from Pinus. The inter- and intra- cellular root colonization of Phialocephala on Pinus has been previously documented and is likely a widespread phenomenon that may be involved in plant phosphorous and nitrogen uptake (Odell et al. 1993; Jumpponen et al. 1998).

\section{Culturable versus uncultured diversity in fungi}

As with all fungal isolation studies it is hard to determine which species are present on the roots but not detected because culture conditions are not suitable, or whether cultured fungi are active on or in the plant roots. To assess whether we were sampling a biologically relevant fraction of fungi we compared our isolates to sequences from previous 454 amplicon pyrosequencing studies of the Populus rhizosphere (Gottel et al. 2011; Shakya et al. 2013; Bonito et al. 2014). Indeed, many of our isolates are represented in some of the top OTU clusters and groups identified in these studies as part of the core microbiome in the Populus rhizosphere (Supplement 3, Figs $3 \& 4$ ). These include Atractiella sp. Cylindrocarpon pauciseptatum, llyonectria spp., Fusarium oxysporum, Phoma sp., Bionectria ochroleuca, Flagelloscypha sp., Leptodontidium sp., Exophiala sp. and Mortierella spp.. Some fungal isolates were not detected by 454 sequencing, likely due to the fact that fungal isolates were made from different physical samples (culturing is inherently a destructive process) and from a wider diversity of soils and locations than those of published 454 sequence datasets available for comparison. While the function of these root-associated fungi remains to be determined, preliminary results from ongoing re-inoculation studies are showing these taxa have distinct niches in plant roots and interact with their hosts in complex, ecologically important and sometimes beneficial ways. 
Methods based on culturing are known to favor rapidly growing fungi, saprotrophs, and otherwise. Symbiotic biotrophic fungi such as ectomycorrhizal species are notoriously difficult to isolate. We clearly were not able to isolate all the fungi from the sampled plants and many of the EcM species that have been detected on Populus (e.g. species of Hebeloma, Inocybe, Laccaria, Tomentella, Tuber, etc.) were absent from our culture collection (Supplementary table 3). While we made great effort to isolate ectomycorrhizal fungi (EcM) we were only successful in isolating a few putative EcM species from Populus (Tuber mexiusanum) (Guevara et al. 2013) and from Pinus (Thelephoraceae sp. and Clavulina sp.). Sequence comparisons to GenBank indicate that the Thelephoraceae species is a common uncultured environmental sequence from roots, while the Clavulina sequence is unique (closest Blast match of $96 \%$ similarity). We also obtained an isolate of Laccaria cf. proxima from fruit bodies produced by trapplants in the growth chamber.

Many unique and rarely-cultured fungi were isolated from Populus. For instance, two ITS OTUs were isolated belonging to the genus Atractiella (Basidiomycota: Puccinomycotina). One species was only isolated once, while the other was isolated from CA and NC soils and from both Populus species. Both are quite distinct from taxonomically identified sequences in GenBank although related to other environmental sequences. Our field studies indicate that this second Atractiella isolate is often in the top 5 fungal OTUs in rhizosphere and endosphere samples of $P$. deltoides (Gottel et al. 2011). Likewise, isolated OTUs belonging to the Chaetosphaeriales, Sordariomycetes, and Heliotiales were difficult to identify due to either few sequences in GenBank that were close matches, or a lack of curated reference sequences for phylogenetic comparisons. Many of the best BLAST matches of these sequences were from insufficiently identified environmental sequences of uncultured fungi.

The growth rates of the fungi isolated in this study varies widely. Some isolates such as those belonging to Mortierella, Fusarium, Umbelopsis, Atractiella and Flagelloscypha grow readily in standard malt extract agar (MEA) filling a $15 \mathrm{~cm}$ petri dish within 1-2 weeks. In contrast, many of the isolates belonging to the Sordariomycetes, Heliotiales, 
Corticiales and Thelephoraceae grew more slowly on the culture media that we used (MEA, MNN), requiring many months to fill a $15 \mathrm{~cm}$ petri dish. Growth on artificial substrates may be a proxy for the function of endorrhizal fungi in nature. We expect that endorrhizal fungi are involved in a range of strategies for acquiring and maintaining necessary resources for their life cycle, including the decomposition of dead organic matter.

The fast growing woody plant species Populus trichocarpa was the first woody plant to have a sequenced and annotated genome and it has emerged as a model species in plant biology (Tuskan et al. 2006). The vision of Populus as a model system was expanded through the Poplar Mesocosm Sequencing project initiated by the Joint Genome Institute (JGI) (Martin et al. 2004). This project resulted in genome sequences of three Populus-associated fungi: the ectomycorrhizal basidiomycete Laccaria bicolor; the arbuscular mycorrhizal fungus Glomus intraradices (Rhizophagus irregularis) and the poplar leaf rust Melampsora larici-populina. Important discoveries continue to emerge from this project including identification of quantitative trait loci important to ectomycorrhizal colonization (Labbe et al. 2011), the identification of effector molecules produced by $L$. bicolor involved in the initiation of ectomycorrhizal formation (Plett et al. 2011), and the expansion of mating type genes in the Glomeromycota (Tisserant et al. 2013; Riley et al. 2014). While fungal root endophytes have been studied for over a century and are known to have important contributions to plant physiology and health (Trowbridge and Jumpponen 2004; Summerbell 2005; Porras-Alfaro and Bayman 2011), there is renewed interest in studying functions of endorrhizal fungi and their interactions with each other, EcM fungi and plants in the context of the plant microbiome. Indeed, many of the endorrhizal fungal isolates obtained in this study are of particular interest given their habit and abundance in the Populus root microbiome. In addition, a large proportion of the isolates are likely to be undescribed species and their ecology within the Populus rhizosphere remains poorly understood. For these reasons a number of genomes from these isolates are being sequenced through the Joint Genome Institute as part of the "Metatranscriptomics of Forest Soil Ecosystems" and "1000 Fungal Genomes" community sequencing projects (Spatafora et al. 2013). These 
include isolates of the novel Atractiella sp. (PMI 95), Mortierella elongate (AG77), llyonectria europaea (PMI 82), Leptodontidium sp. (PMI 412), Flagelloscypha sp. (PMI 526), Lechythophora sp. (PMI 546), Thozetella sp. (PMI 491), Lachnum sp. (PMI 789) and Clavulina sp. (PMI 390). Doing so will expand upon the Poplar Mesocosm Sequencing project that began a decade ago. This culture library is a valuable community resource for studying the functional roles of endophytic root diversity on the growth and health of host plants.

\section{Acknowledgements}

This research was sponsored by the Genomic Science Program, U.S. Department of Energy, Office of Science - Biological and Environmental Research as part of the Plant Microbe Interfaces Scientific Focus Area (http://pmi.ornl.gov). We thank Lee Gunter, Jud Isebrands, Zachary Moore, Paul Bloese and Bernard G. McMahon for supplying Populus cuttings used in this experiment. We are grateful and Natalie Vande Pol and Gian Benucci for their computational assistance. Oak Ridge National Laboratory is managed by UT- Battelle, LLC, for the U.S. Department of Energy under contract DEAC05-00OR22725. GB acknowledges AgBioResearch and Michigan State University for support.

\section{References}

Altschul SF, Gish W, Miller W, Myers EW, Lipman DJ, 1990. Basic local alignment search tool. Journal of Molecular Biology. 215:403-410.

Baum C, Makeschin F, 2000. Effects of nitrogen and phosphorus fertilization on mycorrhizal formation of two poplar clones (Populus trichocarpa and P.tremula $x$ tremuloides). Journal of Plant Nutrition and Soil Science-Zeitschrift Fur Pflanzenernahrung Und Bodenkunde 163 (5):491-497

Beauchamp VB, Stromberg JC, Stutz JC, 2005. Interactions between Tamarix ramosissima (saltcedar), Populus fremontii (cottonwood), and mycorrhizal fungi: Effects on seedling growth and plant species coexistence. Plant and Soil 275 (1-2):221-231

Bois G, Piche Y, Fung MYP, Khasa DP, 2005 Mycorrhizal inoculum potentials of pure reclamation materials and revegetated tailing sands from the Canadian oil sand industry. Mycorrhiza 15 (3):149-158

Bonito G, Reynolds H, Robeson MS, Nelson J, Hodkinson BP, Tuskan G, Schadt CW, Vilgalys R, 2014. Plant host and soil origin influence fungal and bacterial assemblages in the roots of woody plants. Molecular Ecology 23 (13):3356-3370. doi:Doi 10.1111/Mec.12821 
Courty PE, Labbe J, Kohler A, Marcais B, Bastien C, Churin JL, Garbaye J, Le Tacon F, 2011. Effect of poplar genotypes on mycorrhizal infection and secreted enzyme activities in mycorrhizal and non-mycorrhizal roots. Journal of Experimental Botany 62 (1):249-260

Cripps CL, Miller OK, 1995. Ectomycorrhizae Formed in-Vitro by Quaking Aspen - Including Inocybe lacera and Amanita pantherina. Mycorrhiza 5 (5):357-370. doi:Doi 10.1007/Bf00207408

Edgar RC, 2004. MUSCLE: a multiple sequence alignment method with reduced time and space complexity. Bmc Bioinformatics 5:1-19

Edgar RC, 2010. Search and clustering orders of magnitude faster than BLAST. Bioinformatics 26 (19):2460-2461. doi:Doi 10.1093/Bioinformatics/Btq461

Gardes M, White TJ, Fortin JA, Bruns TD, Taylor JW, 1991. Identification of Indigenous and Introduced Symbiotic Fungi in Ectomycorrhizae by Amplification of Nuclear and Mitochondrial Ribosomal DNA. Canadian Journal of Botany-Revue Canadienne De Botanique 69 (1):180-190

Gottel NR, Castro HF, Kerley M, Yang ZM, Pelletier DA, Podar M, Karpinets T, Uberbacher E, Tuskan GA, Vilgalys R, Doktycz MJ, Schadt CW, 2011. Distinct Microbial Communities within the Endosphere and Rhizosphere of Populus deltoides Roots across Contrasting Soil Types. Applied and Environmental Microbiology 77 (17):5934-5944

Guevara G, Bonito G, Trappe JM, Cazares E, Williams G, Healy RA, Schadt C, Vilgalys R, 2013. New North American truffles (Tuber spp.) and their ectomycorrhizal associations. Mycologia 105 (1):194209. doi:Doi 10.3852/12-087

Helm DJ, Allen EB, Trappe JM, 1996. Mycorrhizal chronosequence near Exit Glacier, Alaska. Canadian Journal of Botany-Revue Canadienne De Botanique 74 (9):1496-1506

Jabeen S, Ilyas S, Niazi ARK, Khalid AN, 2012. Diversity of Ectomycorrhizae Associated with Populus Spp. Growing in Two Different Ecological Zones of Pakistan. Int J Agric Biol 14 (5):681-688

Jumpponen A, Mattson KG, Trappe JM, 1998. Mycorrhizal functioning of Phialocephala fortinii with Pinus contorta on glacier forefront soil: interactions with soil nitrogen and organic matter. Mycorrhiza 7 (5):261-265

Kaldorf M, Koch B, Rexer KH, Kost G, Varma A, 2005. Patterns of interaction between Populus Esch5 and Piriformospora indica: A transition from mutualism to antagonism. Plant Biology 7 (2):210-218

Karliński L, Rudawska M, Kieliszewska-Rokicka B, Leski T, 2010. Relationship between genotype and soil environment during colonization of poplar roots by mycorrhizal and endophytic fungi. Mycorrhiza 20 (5):315-324

Karlinski L, Rudawska M, Leski T, 2013. The influence of host genotype and soil conditions on ectomycorrhizal community of poplar clones. European Journal of Soil Biology 58:51-58. doi:Doi 10.1016/J.Ejsobi.2013.05.007

Khasa PD, Chakravarty P, Robertson A, Thomas BR, Dancik BP, 2002. The mycorrhizal status of selected poplar clones introduced in Alberta. Biomass Bioenerg 22 (2):99-104. doi:Pii S09619534(01)00072-1

Klironomos JN, Rillig MC, Allen MF, Zak DR, Kubiske M, Pregitzer KS, 1997. Soil fungal-arthropod responses to Populus tremuloides grown under enriched atmospheric $\mathrm{CO} 2$ under field conditions. Global Change Biology 3 (6):473-478

Labbe J, Jorge V, Kohler A, Vion P, Marcais B, Bastien C, Tuskan GA, Martin F, Le Tacon F, 2011. Identification of quantitative trait loci affecting ectomycorrhizal symbiosis in an interspecific $F(1)$ poplar cross and differential expression of genes in ectomycorrhizas of the two parents: Populus deltoides and Populus trichocarpa. Tree Genetics \& Genomes 7 (3):617-627

Lodge DJ, 1989. The Influence of Soil-Moisture and Flooding on Formation of Va-Endomycorrhizae and Ectomycorrhizae in Populus and Salix. Plant and Soil 117 (2):243-253. doi:Doi 10.1007/Bf02220718 
Maddison WP, Maddison DR, 2009. Mesquite: a modular system for evolutionary analysis. Version 2.6 edn. http://mesquiteproject.org,

Martin F, Tuskan GA, DiFazio SP, Lammers P, Newcombe G, Podila GK, 2004. Symbiotic sequencing for the Populus mesocosm. New Phytologist 161 (2):330-335

Mueller KE, Hobbie SE, Oleksyn J, Reich PB, Eissenstat DM, 2012. Do evergreen and deciduous trees have different effects on net $\mathrm{N}$ mineralization in soil? Ecology 93 (6):1463-1472

Nilsson RH, Veldre V, Hartmann M, Unterseher M, Amend A, Bergsten J, Kristiansson E, Ryberg M, Jumpponen A, Abarenkov K, 2010. An open source software package for automated extraction of ITS1 and ITS2 from fungal ITS sequences for use in high-throughput community assays and molecular ecology. Fungal Ecology 3 (4):284-287

Odell TE, Massicotte HB, Trappe JM, 1993. Root Colonization of Lupinus latifolius Agardh and Pinus contorta Dougl by Phialocephala fortinii Wang and Wilcox. New Phytologist 124 (1):93-100

Plett JM, Kemppainen M, Kale SD, Kohler A, Legue V, Brun A, Tyler BM, Pardo AG, Martin F, 2011. A Secreted Effector Protein of Laccaria bicolor Is Required for Symbiosis Development. Current Biology 21 (14):1197-1203. doi:Doi 10.1016/J.Cub.2011.05.033

Podila GK, Sreedasyam A, Muratet MA, 2009. Populus Rhizosphere and the Ectomycorrhizal Interactome. Critical Reviews in Plant Sciences 28 (5):359-367

Porras-Alfaro A, Bayman P, 2011. Hidden Fungi, Emergent Properties: Endophytes and Microbiomes. Annu Rev Phytopathol 49:291-315. doi:Doi 10.1146/Annurev-Phyto-080508-081831

Riley R, Charron P, Idnurm A, Farinelli L, Dalpe Y, Martin F, Corradi N, 2014. Extreme diversification of the mating type-high-mobility group (MATA-HMG) gene family in a plant-associated arbuscular mycorrhizal fungus. New Phytologist 201 (1):254-268. doi:Doi 10.1111/Nph.12462

Schoch CL, Seifert KA, Huhndorf S, Robert V, Spouge JL, Levesque CA, Chen W, Bolchacova E, Voigt K, Crous PW, Miller AN, Wingfield MJ, Aime MC, An KD, Bai FY, Barreto RW, Begerow D, Bergeron MJ, Blackwell M, Boekhout T, Bogale M, Boonyuen N, Burgaz AR, Buyck B, Cai L, Cai Q, Cardinali G, Chaverri P, Coppins BJ, Crespo A, Cubas P, Cummings C, Damm U, de Beer ZW, de Hoog GS, Del-Prado R, B D, Dieguez-Uribeondo J, Divakar PK, Douglas B, Duenas M, Duong TA, Eberhardt U, Edwards JE, Elshahed MS, Fliegerova K, Furtado M, Garcia MA, Ge ZW, Griffith GW, Griffiths K, Groenewald JZ, Groenewald M, Grube M, Gryzenhout M, Guo LD, Hagen F, Hambleton S, Hamelin RC, Hansen K, Harrold P, Heller G, Herrera G, Hirayama K, Hirooka Y, Ho HM, Hoffmann K, Hofstetter V, Hognabba F, Hollingsworth PM, Hong SB, Hosaka K, Houbraken J, Hughes K, Huhtinen S, Hyde KD, James T, Johnson EM, Johnson JE, Johnston PR, Jones EB, Kelly LJ, Kirk PM, Knapp DG, Köljalg U, GM K, Kurtzman CP, Landvik S, Leavitt SD, Liggenstoffer AS, Liimatainen K, Lombard L, Luangsa-Ard JJ, Lumbsch HT, Maganti H, Maharachchikumbura SS, Martin MP, May TW, McTaggart AR, Methven AS, Meyer W, Moncalvo JM, Mongkolsamrit S, Nagy LG, Nilsson RH, Niskanen T, Nyilasi I, Okada G, Okane I, Olariaga I, Otte J, Papp T, Park D, Petkovits T, PinoBodas R, Quaedvlieg W, Raja HA, Redecker D, T R, Ruibal C, Sarmiento-Ramirez JM, Schmitt I, Schussler A, Shearer C, Sotome K, Stefani FO, Stenroos S, Stielow B, Stockinger H, Suetrong S, Suh SO, Sung GH, Suzuki M, Tanaka K, Tedersoo L, Telleria MT, Tretter E, Untereiner WA, Urbina $H$, Vagvolgyi C, Vialle A, Vu TD, Walther G, Wang QM, Wang Y, Weir BS, Weiss M, White MM, Xu J, Yahr R, Yang ZL, Yurkov A, Zamora JC, Zhang N, Zhuang WY, Schindel D, Fungal Barcoding Consortium, 2012. Nuclear ribosomal internal transcribed spacer (ITS) region as a universal DNA barcode marker for Fungi. Proceedings of the National Academy of Sciences of the United States of America 109 (16):6241-6246

Shakya M, Gottel N, Castro H, Yang Z, Gunter L, Labbé J, Muchero W, Bonito G, Vilgalys R, Tuskan G, Podar M, Schadt CW, 2013. A Multifactor Analysis of Fungal and Bacterial Community Structure in the Root Microbiome of Mature Populus deltoides Trees. PLOS one 8 (10):e76382. doi:10.1371/journal.pone.0076382 
Slavov GT, DiFazio SP, Martin J, Schackwitz W, Muchero W, Rodgers-Melnick E, Lipphardt MF, Pennacchio CP, Hellsten U, Pennacchio LA, Gunter LE, Ranjan P, Vining K, Pomraning KR, Wilhelm LJ, Pellegrini M, Mockler TC, Freitag M, Geraldes A, El-Kassaby YA, Mansfield SD, Cronk QCB, Douglas CJ, Strauss SH, Rokhsar D, Tuskan GA, 2012. Genome resequencing reveals multiscale geographic structure and extensive linkage disequilibrium in the forest tree Populus trichocarpa. New Phytologist 196 (3):713-725. doi:Doi 10.1111/J.1469-8137.2012.04258.X

Smith SE, Read DJ, 2008. Mycorrhizal Symbiosis. 3rd edition edn. Academic Press, Spatafora J, Stajich J, Grigoriev I, 2013. 1000 Fungal Genomes project. Phytopathology 103 (6):137-137

Summerbell RC, 2005. From Lamarckian fertilizers to fungal castles: recapturing the pre-1985 literature on endophytic and saprotrophic fungi associated with ectomycorrhizal root systems. Studies in Mycology (53):191-256

Swofford DL, 2002. PAUP* Phylogenetic analysis using parsimony (*and other methods). 4.0 edn. Sinauer Associates, Sunderland, Massachusetts

Thorn RG, Reddy CA, Harris D, Paul EA, 1996. Isolation of saprophytic basidiomycetes from soil. Applied and Environmental Microbiology 62 (11):4288-4292

Tisserant E, Malbreil M, Kuo A, Kohler A, Symeonidi A, Balestrini R, Charron P, Duensing N, Frey NFD, Gianinazzi-Pearson V, Gilbert LB, Handa Y, Herr JR, Hijri M, Koul R, Kawaguchi M, Krajinski F, Lammers PJ, Masclauxm FG, Murat C, Morin E, Ndikumana S, Pagni M, Petitpierre D, Requena N, Rosikiewicz P, Riley R, Saito K, Clemente HS, Shapiro H, Van Tuinen D, Becard G, Bonfante P, Paszkowski U, Shachar-Hill YY, Tuskan GA, Young PW, Sanders IR, Henrissat B, Rensing SA, Grigoriev IV, Corradi N, Roux C, Martin F, 2013. Genome of an arbuscular mycorrhizal fungus provides insight into the oldest plant symbiosis. Proceedings of the National Academy of Sciences of the United States of America 110 (50):20117-20122. doi:Doi 10.1073/Pnas.1313452110

Trowbridge J, Jumpponen A, 2004. Fungal colonization of shrub willow roots at the forefront of a receding glacier. Mycorrhiza 14 (5):283-293

Vilgalys R, Hester M, 1990. Rapid Genetic Identification and Mapping of Enzymatically Amplified Ribosomal DNA from Several Cryptococcus Species. J Bacteriol 172 (8):4238-4246

Visser S, Maynard D, Danielson RM, 1998. Response of ecto- and arbuscular mycorrhizal fungi to clearcutting and the application of chipped aspen wood in a mixedwood site in Alberta, Canada. Applied Soil Ecology 7 (3):257-269. doi:Doi 10.1016/S0929-1393(97)00060-7

Zhang XY, Liang J, Sun ZQ, Qu ZW, Zhang Y, Lu Q, 2010. Long-term effect of an ectomycorrhizal inoculum and other treatments on survival and growth of Populus hopeiensis Hu et Chow. Forest Ecology and Management 259 (12):2223-2232

Zhong Z, 1995. Research on mycorrhizal associations of poplar. Mycorrhizas for Plantation Forestry in Asia (62):62-66

Figure 1 - Culture macro-morphology of 12 fungal isolates that were commonly detected in culture independent analyses of Populus roots. A. Atractiella rhizophilia nom. prov. PMI 95; B. Bionectria ochroleuca PMI 827; C. Exophiala sp. PMI 424; D. Flagelloscypha sp. PMI 526; E. Fusarium PMI 1211; F. Ilyonectria sp. PMI 1211; G. Leptodontidium sp. PMI 1412; H. Mortierella elongata PMI 93; I. Neonectria sp. PMI 83; J. Neonectria sp. PMI 1677; K. Phomopsis sp. PMI 847; L. Sordariales PMI 418. 
Figure 2 - Rank abundance plots of fungal isolates from specific plant hosts. A. Populus trichocarpa. B. Populus deltoides. C. Quercus alba. D. Pinus taeda.

Figure 3 - Phylogenetic affinities of fungal isolates based on 28S rDNA analysis. Plant host from which root-associated fungi were isolated from is color coded on the outer ring (Populus trichocarpa - yellow; Populus deltoids - dark green; Pinus taeda light green; Quercus alba - orange). Region from where the isolates originate is color coded in middle ring (West coast of North America - shades of blue; Eastern North America - green). Taxonomic affinity of isolates are color coded on the phylogenetic tree as indicated inner key.

Figure 4 - Correspondance between fungi isolated from the Populus rhizosphere and those detected by 454 amplicon pyrosequencing. A. Venn diagram showing the overlap between cultured fungal isolates and those generated from 454 amplicon pyrosequencing as reported by Bonito et al. (2014). B. Top ten ranked sequenced fungi from the Populus rhizosphere and their corresponding representation in cultured isolates. 


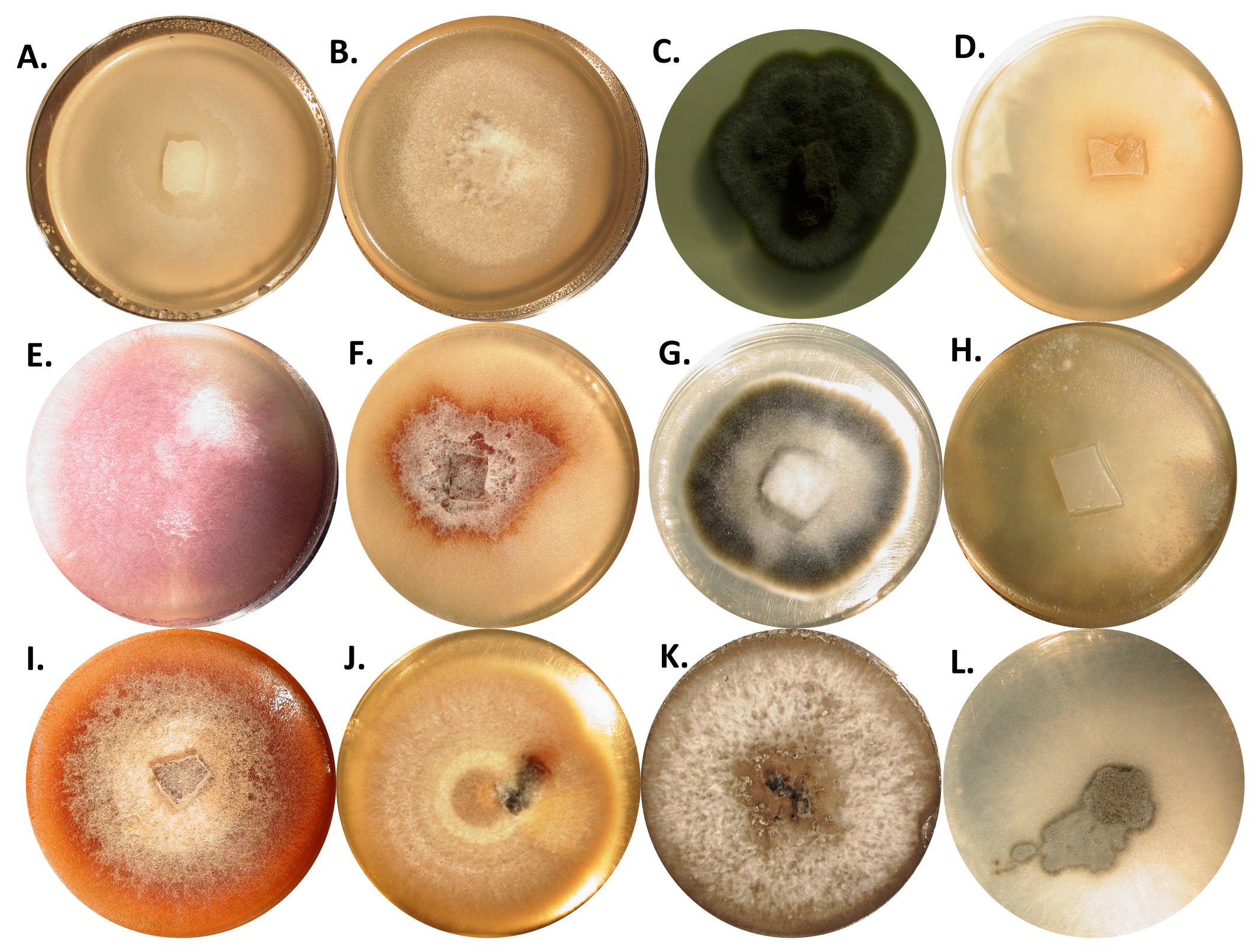



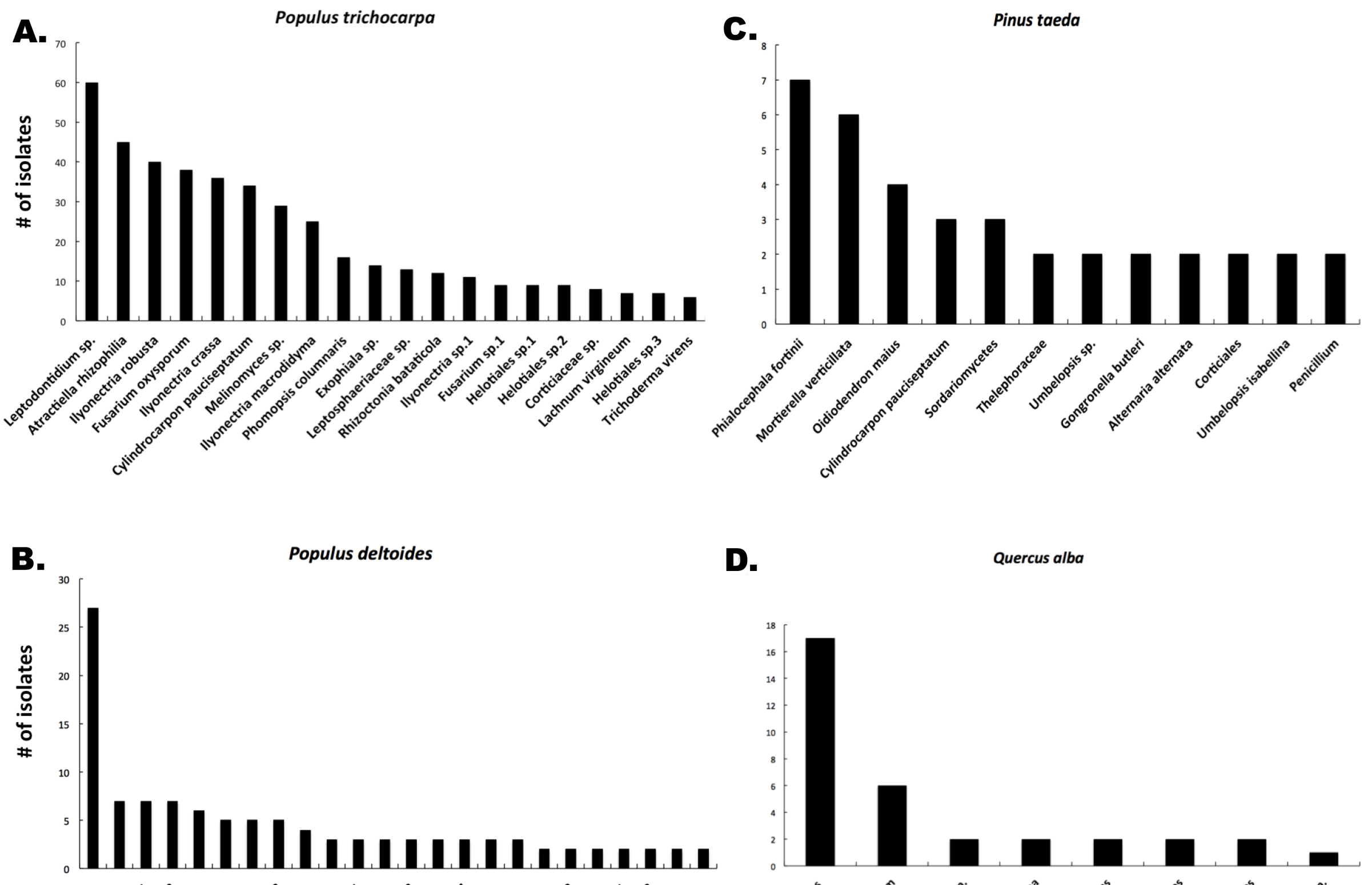

D. Quercus alba
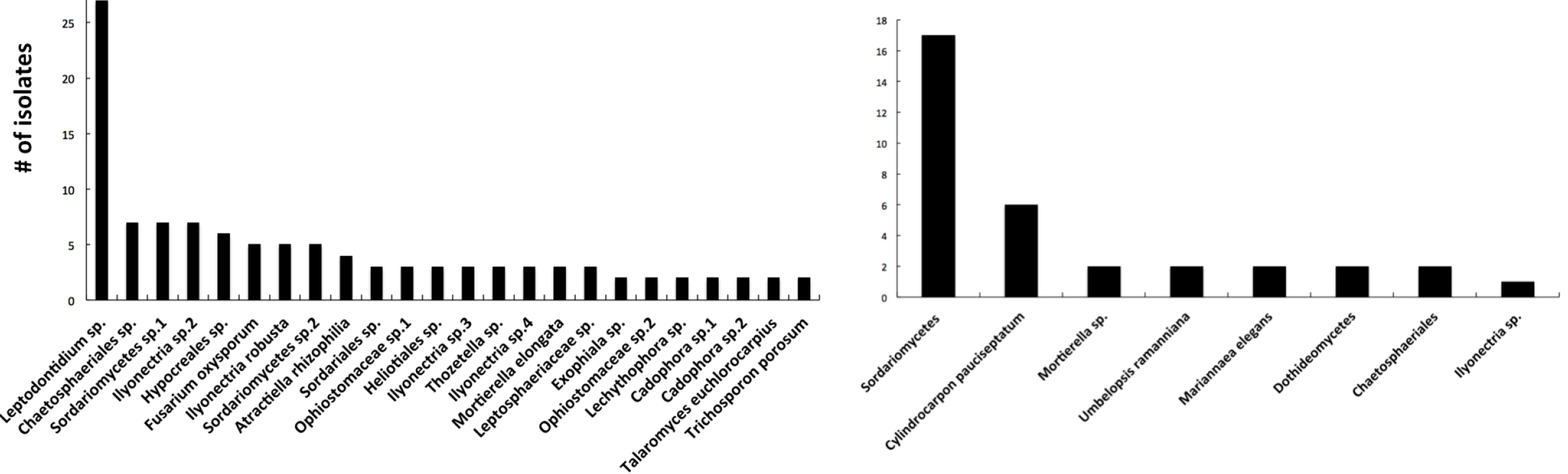
A.

\section{Populus trichocarps}

B.

BC

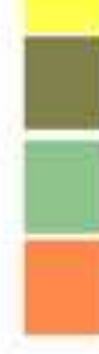

Populua deltoides

Pinus taeda

Quercus alba

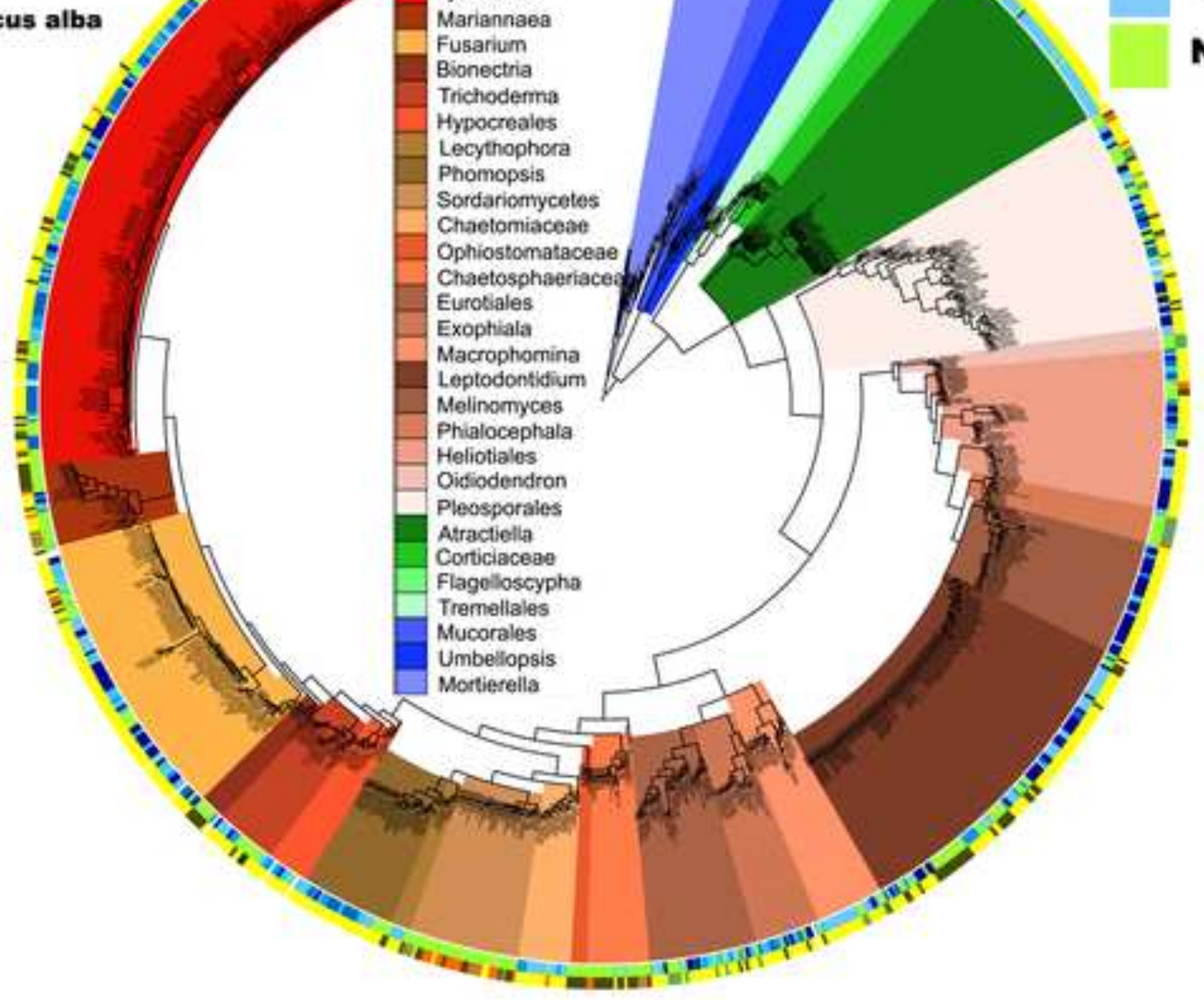

WA

OR

CA

NC 

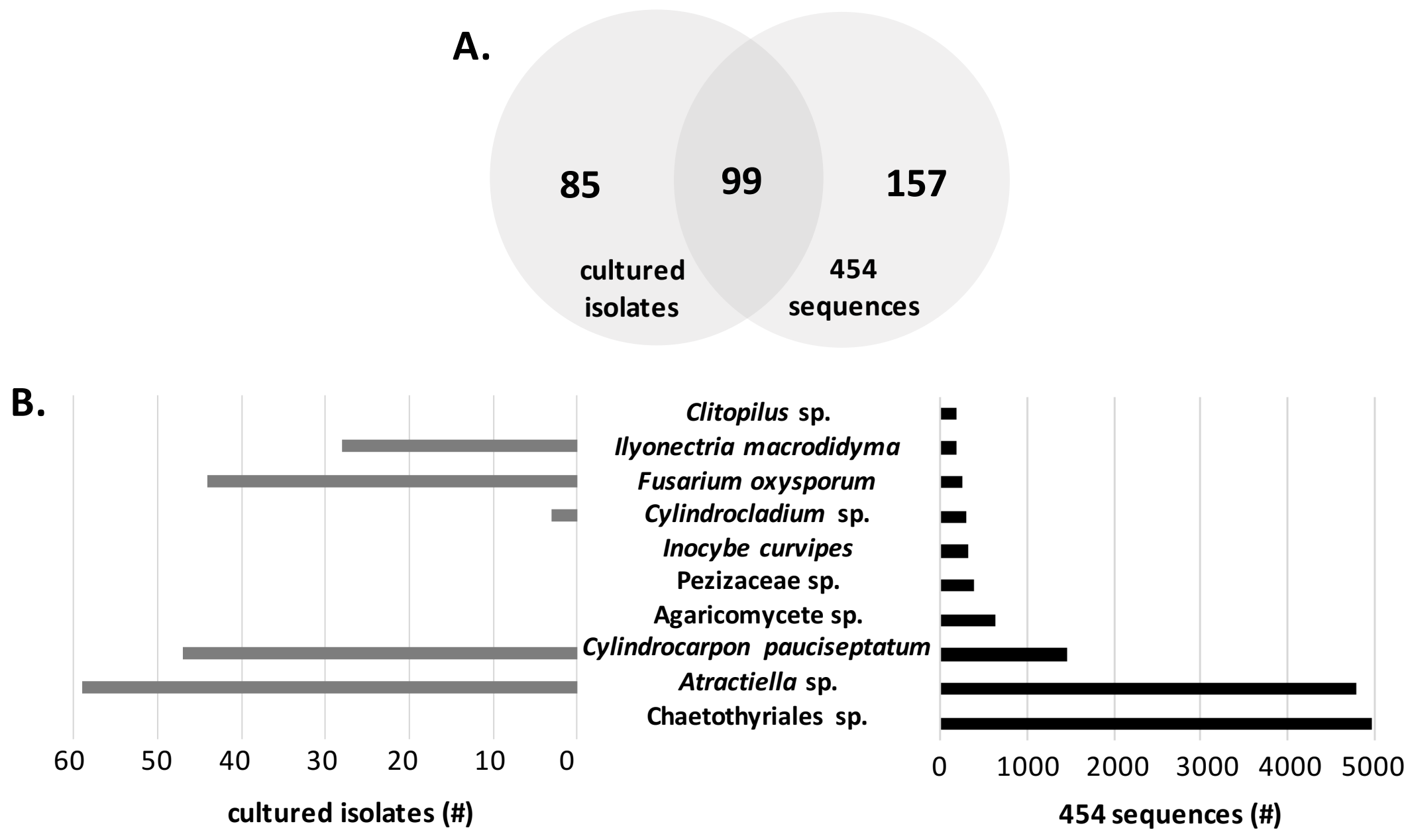